\title{
Primate study may yield new CJD clues ...
}

[PARIS] A study published last week that appears to show that primates are easily infected orally with bovine spongiform encephalopathy (BSE) may, if confirmed, have implications for the understanding of the new variant of Creutzfeldt-Jakob disease (vCJD) in humans.

The study could also provide a better and faster animal research model than those currently available. But researchers are angry that more extensive primate experiments, recommended to the European Commission in 1996 by one of its expert committees, have not been supported (see below). This reluctance, argue some scientists, stemmed from opposition in a number of member states to research using primates.

Two young Microcebus murinus lemurs, fed $0.5 \mathrm{~g}$ of cattle brain infected with the agent that causes BSE and autopsied five months later, were found to have prion infections, despite showing no outward clinical signs of the disease. Three control animals showed no signs of infection.

The group also autopsied two symptomatic and 18 apparently healthy large monkeys and lemurs from French zoos that had eaten animal feed produced in the United Kingdom. All were found to be infected.

The work was published in the 30 March issue of the Proceedings of the National Academy of Sciences (PNAS) by a Franco-American team including Noëlle Bons of the University II of Montpellier, Paul Brown of the US National Institute of Neurological Disor-

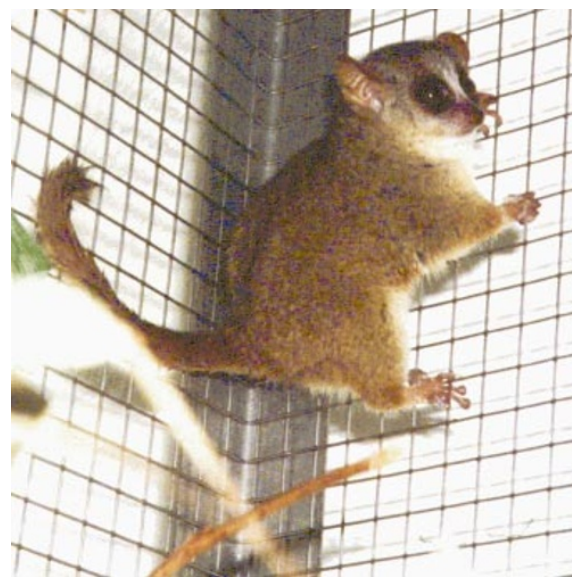

Model subject? Lemurs may be good animals for studying spongiform diseases.

ders and Stroke in Bethesda, Maryland, and D. Carleton Gajdusek, the 1976 Nobel prize winner for his work on prions, now at the Institut Alfred Fessard near Paris.

Charles Weissman, from the University of Zürich, in Switzerland, points out that a major caveat in the study is that infection was assessed by immunostaining of proteinaseresistant prion protein, rather than by Western blotting of abnormal prion protein. Fixed brain samples which cannot be tested using a blot were taken at the time, explains Bons, adding that ongoing experiments will use frozen samples and Western blotting.

At the same time, Weissmann - who chaired the committee that advocated more

\section{as researchers fume over blocked research}

[PARS] Dominique Dormont, a prion expert who is head of the French government's spongiform encephalopathy advisory committee, is - like many BSE/CJD researchers dismayed at what he claims are the years lost because of an apparent lack of political support for work using primates.

Dormont says that a proposal for experiments on macaques, submitted in 1996, was not approved because some states including the United Kingdom - opposed it on animalwelfare grounds.

Large-scale primate experiments can only be carried out at a continental level, says Dormont, because of the high costs and logistics. He says that some countries felt such experiments would be a waste of money, as, by the time their results came through, the results of human exposure to BSE would already be beginning to appear.

Paul Brown, of the US National Institute of Neurological Disorders and Stroke, one of the authors of the PNAS paper (see above), adds that he advocated similar experiments in the United States at roughly the same time. But he claims that government safety restrictions on BSE and VCJD materials have all but halted research.

"I can understand that they don't want every Tom, Dick and Harry working on these agents," says Brown. "But the regulations are blocking all research in the handful of labs who have forty years experience handling these agents."

Noëlle Bons, from the University II of Montpellier, another author of the paper, wrote to Edith Cresson, the then European commissioner for research, in 1998, presenting her with the preliminary results of the PNAS paper. She also complained that she had heard nothing regarding a research proposal on BSE she had submitted the previous year. Bons claims that, despite meeting a member of Cresson's staff, she remains in the dark as to support for her project. primate studies in 1996 - says that he hopes the new findings may encourage more interest in these. The findings, if confirmed, could have "very worrisome implications" for humans, he adds, as they suggest that primates closely related to us may be highly susceptible to oral transmission of BSE.

Dominique Dormont, whose group demonstrated the first transmission of BSE to a macaque (see Nature 381, 743; 1996), points out that Microcebus murinus may be a valuable new animal model. This tiny species weighs just 100 grammes and has a short lifespan of eight to ten years, making it much more suitable for research than macaques and other larger, longer-lived primates.

According to Bons, another lemur from another experiment has fallen ill with symptoms of spongiform encephalopathy one year after being fed contaminated cattle brain. The short time to incubation and illness suggest the species would be ideal for research purposes, she says, warning at the same time against the dangers of extrapolating results directly to humans.

In the experimental PNAS study, infection was found throughout the tonsils and peripheral tissues, and confirms an oral route of transmission of BSE, says Dormont. The agent appears to pass through the digestive tract, across the spleen, and up the spinal cord into the brain, says Brown.

Bons argues that the results also suggest that nervous degeneration and wide peripheral infection occurs early in the incubation phase, raising the prospect that in humans asymptomatic individuals could be carrying high levels of infections - which might have implications for secondary transmission. "We know nothing of the kinetics of vCJD in humans [where living individuals cannot be autopsied]," says Brown, arguing that primate studies could therefore yield new information on this.

The dose of brain fed to the lemurs is equivalent to a $70 \mathrm{~kg}$ man eating a dose of 500 g. The larger experiments needed to establish the minimum dose needed for infection could not be carried out, however. This is "unfortunate," says Weissmann, pointing out that his committee called in 1996 for precisely such experiments, as well as ones on maternal transmission.

Bons is also studying two baby lemurs born from infected parents. She says she is collecting samples to establish whether and how maternal transmission occurs.

The PNAS paper contains another potentially controversial element. According to Bons, the the only meat in the zoo primates' food was British 'cretons de bouf', a meat residue approved for human consumption. A fuller inquiry into the source of infection is needed, she says.

Declan Butler 